\title{
Cuerpos para el trabajo. Una mirada sobre la gestión de los trastornos de la salud de las trabajadoras domésticas migrantes ${ }^{1}$
}

\author{
María Offenhenden \\ Doctoranda en Antropología, URV \\ mariaoffenhenden@yahoo.com.ar
}

Resumen: En este artículo presentamos los resultados de la investigación realizada en relación con la experiencia de enfermedad durante la migración para el caso de las mujeres migrantes latinoamericanas empleadas en el trabajo doméstico residentes en Cataluña. Convencidos de la necesidad de profundizar en el conocimiento de la situación de los migrantes a lo largo de todo el proceso migratorio, intentamos analizar $y$ describir la experiencia de enfermedad de estas trabajadoras en cuanto experiencia vital desestructurante que necesariamente altera el precario equilibrio construido en la sociedad de destino y condiciona su proyecto migratorio, muchas veces estrechamente vinculado al sostén de sus unidades familiares, ya sea en la sociedad de origen $y / o$ de destino.

Palabras clave: migraciones femeninas latinoamericanas; trabajo doméstico; experiencia de enfermedad.

Abstract: This paper presents the results of research carried out in relation to the illness experience during migration of Latina women employed as domestic workers in Catalonia. In order to deepen understanding of the migrants' condition throughout the entire migration process, we analyze and describe the illness experience of these migrant workers as a destructuring life experience that necessarily alters the delicate balance built into the host society and affects their migratory project, which is often closely linked to supporting their households in their society of origin and/or destination.

Keywords: Latina female migrations; domestic workers; illness experience.

1. Agradezco a Yolanda Bodoque la atenta revisión de este escrito. 


\section{Migración, trabajo y salud el caso de las empleadas domésticas latinoamericanas residentes en Cataluña ${ }^{2}$}

La literatura especializada en las actuales migraciones internacionales femeninas señala que frecuentemente estas obedecen a una estrategia de supervivencia de la unidad familiar en la que mujeres-madres practican a distancia su rol social de cuidadoras (Ehrenreich y Hochschild, 2004; Parreñas, 2001; Sanz, 2007). Muchas mujeres migran para realizar tareas de asistencia y cuidado en familias del norte rico, convirtiendo su adscripción doméstica en una tarea remunerada con dedicación a tiempo completo (Ehrenreich y Hochschild, 2004; Parreñas, 2001). Paradójicamente, solo por medio de la separación de sus familias y atendiendo a las necesidades de otras pueden cumplir transnacionalmente con el rol que social y culturalmente se les ha asignado.

Se constituyen las llamadas familias transnacionales, en las que mujeresmadres-jefas de familia practican la maternidad transnacionalmente (Hondagneu-Sotelo y Ozyegin, 2008; Parreñas, 2001) por medio de cadenas mundiales de cuidados y afectos, una "[...] serie de vínculos personales entre gente de todo el mundo, basadas en una labor remunerada o no remunerada de asistencia" (Hochschild, 2001:188), generalmente conformadas por mujeres que se relacionan entre sí a través del cuidado de los hijos y/o adultos dependientes de la mujer que está "ausente" del hogar por motivos laborales, tanto en la sociedad de destino como en la de origen.

Lo anterior es especialmente cierto para el caso de las mujeres latinoamericanas, que suelen ser las protagonistas de las primeras fases del proyecto migratorio y que en la sociedad de destino en la que realizamos nuestra investigación, Cataluña, constituyen uno de los colectivos con mayores índices de feminización y una importante participación en el sector de los servicios, especialmente en el trabajo doméstico.

Sin embargo, se ha cuestionado que sean solo motivos económicos los que inducen a las mujeres a migrar. Si bien lo económico suele tener un peso muy importante, es común que se entrelace con otras motivaciones tales como alejarse de una relación conyugal poco satisfactoria, escapar de situaciones fami-

2. A lo largo de este artículo nos referiremos al trabajo doméstico y a las trabajadoras domésticas en el sentido amplio del término. Siguiendo a Parreñas (2001), por trabajadoras domésticas entendemos las empleadas pagadas por individuos o familias para realizar tareas de cuidados de ancianos o niños y/o realizar tareas de limpieza en el ámbito privado del hogar. 
liares y/o sociales violentas (Guarnizo y Sørensen, 2007) e, inclusive, formar una nueva familia en destino (Bodoque y Soronellas, 2010).

Algunas investigaciones han señalado que con la migración las mujeres logran renegociar los roles de género e inclusive llegar a subvertirlos (Morokvasic, 2007; Pedone, 2006; Sanz, 2007). Pero su estrategia migratoria no está libre de conflictos. Muchas migrantes cargan con el sentimiento de culpa que genera el abandono de sus hijos, sentimiento reforzado en el país de origen por políticos, medios de comunicación y otros agentes conformadores de opinión que las acusan de destructoras de hogares (Pedone, 2006; Sanz 2007).

Con la migración a menudo las mujeres pueden mejorar las condiciones de existencia material para ellas y para sus familias. Por ello, junto con las recriminaciones, también afloran los elogios por su altruismo en pos de la familia transnacional. El excesivo énfasis en los beneficios económicos que produce la estrategia migratoria femenina ha llevado a cuestionar los efectos no económicos que el ejercicio de la maternidad transnacional tiene en los sujetos más débiles de estas cadenas de cuidados, es decir, los niños que quedan en la sociedad de origen, a los cuales se les niega el afecto materno en contraposición a la "plusvalía de afecto" que reciben los hijos ajenos que cuida la migrante en la sociedad de destino (Hochschild, 2001). Creemos, sin embargo, que en esta discusión, además de reificarse la naturalización del cuidado y los afectos como algo típicamente femenino (Gregorio, 2010), se ha descuidado la reflexión en torno al bienestar de las mujeres durante el proceso migratorio, principal eslabón de esta cadena que la hace posible y sostiene transnacionalmente a costa de enfrentar nuevas y viejas discriminaciones tanto en la sociedad de destino como en la de origen.

De hecho, en el ámbito específico de los estudios migratorios no son numerosas las investigaciones que privilegien una perspectiva fenomenológica del estudio de la enfermedad. Con esto entendemos una experiencia que "afecta a un cuerpo en el mundo" (Good, 2003: 245), que ocurre en un tiempo, en un lugar, en una historia, en un contexto de experiencia vital y en un mundo social. Este vacío podría estar relacionado con el peso que tiene la representación del migrante - generalmente en términos masculinos - como una persona joven y sana. Imagen que desde la academia tiende a reproducirse en su intento (bienintencionado) por desmontar algunos tópicos sobre la inmigración y la sanidad como, por ejemplo, la asociación de la inmigración con la "importación" de 
enfermedades infecciosas o la supuesta mayor utilización del servicio sanitario público por parte de la población extranjera (Burrillo-Putze y Balanzó, 2010).

También se suele recurrir a la imagen del "inmigrante sano" con el fin de resaltar cómo las precarias condiciones de inserción en la sociedad de destino inciden negativamente en su estado de salud (García et alii, 2009; Goldberg, 2003). ${ }^{3}$ En esta línea, algunas investigaciones a nivel nacional han abordado el tema específico de la salud de la mujer migrante y, con ello, la de las trabajadoras domésticas latinoamericanas dada su altísima concentración en esta actividad laboral, donde se revisan, alternativamente, su relación con el sistema de salud público, los efectos de las condiciones de vida y trabajo en su salud física y mental y su autopercepción de salud (Bermúdez, 2004; Bover, 2006; Jiménez y Redondo, 2007; Río et alii, 2003; Gentil, 2009).4

No pretendemos negar el hecho de que la mayoría de los migrantes sean personas jóvenes y de que generalmente gocen de buena salud. Tampoco desestimamos la importancia que revisten las investigaciones hasta ahora realizadas. Pero entendemos que su representación como personas “jóvenes y sanas”, es decir, en condiciones óptimas para trabajar, coincide, siguiendo a Sayad (2002), con la definición preponderante que justifica y legitima el proceso migratorio tanto a los ojos del migrante como a los de su entorno, lo que impide profundizar el análisis en otros aspectos relacionados con la migración.

Por una parte, en el país de inmigración, el inmigrante es definido como un extranjero que reside provisoria (al menos en teoría) y exclusivamente por razones laborales. Por otro lado, en el país de emigración el emigrante es definido como un compatriota que está ausente provisoria (también en teoría) y esencialmente por motivos laborales.

Pero también el migrante legitima y justifica su emigración/inmigración en torno al trabajo. Si tal como la bibliografía especializada señala, buena parte de las mujeres justifica y legitima su migración en función de sus responsabilidades de cuidado hacia sus unidades domésticas, proyecto que materializan por

3. En términos generales, el migrante es presentado como una persona sana que enferma cuando emigra a causa de la falta de acceso a un trabajo normalizado, la irregularidad jurídico-administrativa, las condiciones habitacionales deficitarias, la soledad y el aislamiento.

4. Cabe agregar que cuando se estudia la salud de las mujeres migrantes por lo general tiende a prevalecer en las investigaciones el interés por su salud sexual y reproductiva, privilegiando siempre en el análisis la relación entre la población inmigrante y las instituciones sociosanitarias. Para una revisión sobre las investigaciones realizadas en España en relación con la inmigración y la salud y el caso específico de las mujeres migrantes, remitimos a Bardají (2006: 275-304). 
medio de su empleo en el servicio doméstico en la sociedad de destino, nos preguntamos, ¿qué sucede cuando los problemas de salud impiden trabajar? ¿Qué implicaciones tiene la experiencia de enfermedad en el proyecto migratorio de estas mujeres? Y, sobre todo, ¿quién cuida de ellas cuando enferman?

Aquí presentamos los primeros resultados de la investigación realizada en este sentido, focalizada en el caso particular de las trabajadoras domésticas migrantes latinoamericanas y que constituye una primera aproximación a las preguntas arriba planteadas.

\section{Breve nota metodológica}

Se trata de una investigación de corte cualitativo, realizada entre 2011 y 2012, cuya principal estrategia de campo consistió en trabajar con 7 relatos de vida de mujeres latinoamericanas residentes en Cataluña empleadas en el servicio doméstico que hubiesen sufrido o estuviesen sufriendo un problema de salud.

Las entrevistas incluyeron datos de clasificación, trayectoria migratoria, experiencia de enfermedad y la valoración personal de su experiencia migratoria. La muestra no pretendió ser representativa de un grupo mayor, pero se cuidó que en la selección se combinasen alternativamente variables tales como lugar y fecha de nacimiento, estado civil, composición y lugar de residencia del grupo doméstico y tiempo de residencia en España, entre otras. A continuación se presenta un cuadro en el que se resumen las principales características de la muestra analizada:

Tabla 1. Mujeres entrevistadas

\begin{tabular}{|l|c|c|c|l|l|}
\hline Nombre $^{1}$ & $\begin{array}{c}\text { País } \\
\text { de origen }\end{array}$ & Edad & $\begin{array}{c}\text { Año llegada } \\
\text { España }\end{array}$ & \multicolumn{1}{|c|}{ Familia nuclear } & Problemas de salud revelados $^{2}$ \\
\hline Mirella & Colombia & 61 & 2001 & $\begin{array}{l}\text { Soltera } \\
\text { 3 hijos: uno muerto, una en } \\
\text { Colombia, una en paradero } \\
\text { desconocido. }\end{array}$ & $\begin{array}{l}\text { Tiroides; úlcera; anemia; } \\
\text { problemas cervicales; } \\
\text { artrosis; depresión. }\end{array}$ \\
\hline Susana & Paraguay & 40 & 2003 & $\begin{array}{l}\text { Soltera } \\
1 \text { hijo mayor de edad en } \\
\text { Paraguay. } \\
1 \text { hija menor de edad en } \\
\text { España. }\end{array}$ & $\begin{array}{l}\text { Operación vesícula y quiste } \\
\text { ovario; tendinitis; artrosis } \\
\text { lumbar. }\end{array}$ \\
\hline
\end{tabular}




\begin{tabular}{|l|l|c|c|l|l|}
\hline Marlene & Ecuador & 50 & 2001 & $\begin{array}{l}\text { Divorciada } \\
\text { 3 hijos mayores de edad: una } \\
\text { muerta, una en Ecuador, uno } \\
\text { en España. }\end{array}$ & Depresión; estrés. \\
\hline Roxana & Perú & 42 & 1996 & $\begin{array}{l}\text { Divorciada } \\
\text { 2 hijos mayores de edad: uno } \\
\text { en Perú, uno en España. }\end{array}$ & Insuficiencia renal. \\
\hline Carmen & Colombia & 47 & 2000 & $\begin{array}{l}\text { En pareja } \\
\text { 4hijos mayores de edad: 2 en } \\
\text { Ecuador, 2 en España. } \\
\text { 2 hijos menores de edad en } \\
\text { Ecuador. }\end{array}$ & $\begin{array}{l}\text { Secuelas accidente laboral: } \\
\text { problemas cervicales, } \\
\text { migrañas; anemia; depresión. }\end{array}$ \\
\hline Rosa & Brasil & 36 & 2004 & $\begin{array}{l}\text { En pareja } \\
\text { 3 hijos menores de edad en } \\
\text { Brasil }\end{array}$ & $\begin{array}{l}\text { Accidente laboral: corte en } \\
\text { la mano. }\end{array}$ \\
\hline Mónica & Bolivia & 33 & 2005 & \begin{tabular}{l} 
Soltera sin hijos \\
\hline
\end{tabular}
\end{tabular}

1. Hemos cambiado los nombres de las mujeres para preservar su anonimato.

2. En la identificación de los problemas de salud nos basamos exclusivamente en aquello que las mujeres nos contaron, es decir, en los padecimientos que ellas mismas individuaron en sus narraciones. Nuestra aproximación al problema excluyó una mirada médica profesional y la intención de registrar la morbilidad más usual entre esta población, impracticable dada nuestra formación y que además se aleja de los fines propuestos en esta investigación.

3. Carmen es de nacionalidad colombiana, pero gran parte de su vida antes de venir a España la pasó en Ecuador, país en el que nacieron sus seis hijos.

\section{Condiciones de inserción/exclusión de las trabajadoras domésticas latinoamericanas en la sociedad de acogida}

Antes de entrar en lleno en el tema que nos ocupa, consideramos pertinente hacer referencia a las condiciones de vida y trabajo en Cataluña de las mujeres entrevistadas, contexto ineludible para enmarcar el análisis de su experiencia de enfermedad. Sin pretender ser exhaustivos, a continuación presentamos algunas de las características salientes reveladas en el trabajo de campo.

En primer lugar, como denominador común de todas las historias analizadas aparece un largo período de irregularidad jurídica. Si bien al momento de realizar las entrevistas todas residían regularmente y eran titulares de sus respectivas autorizaciones para trabajar (dos inclusive se habían nacionalizado españolas), al inicio de su estancia en España estuvieron por lo general unos tres años o más "sin papeles". Es más, la irregularidad aparece como una estrategia 
dentro de un proyecto migratorio que al principio se formula como provisorio. Con el aplazo del retorno, la regularización de la residencia cobra importancia, especialmente cuando la redefinición del proyecto migratorio prevé la reagrupación familiar.

También son comunes las dificultades para conseguir una vivienda digna y estable. Todas las mujeres reportaron vivir en condiciones de hacinamiento en viviendas en pésimo estado de conservación en sus primeros años de estancia en Cataluña. Con el tiempo, algunas lograron mejorar esta situación a través del alquiler de una vivienda, especialmente si realizaron la reagrupación familiar. Otras, en cambio, aún no habían conseguido resolver establemente este aspecto si bien llevaban muchos años en Cataluña (no menos de 7 años).

Por otro lado, emergen durísimas condiciones de trabajo, que en algunas ocasiones lindan con la explotación. ${ }^{5}$ Son comunes la irregularidad en la contratación, aun cuando las mujeres ya son titulares de sus autorizaciones de trabajo; largas jornadas laborales en las que a menudo no se respetan ni las horas de descanso ni el horario de salida pactado; bajos salarios; pluriempleo, que elimina los días de descanso; y escasísima movilidad laboral, ya que todas transitan, alternativamente e inclusive al mismo tiempo, por empleos del sector de los servicios (atención a la dependencia y trabajo doméstico - por horas, fijo o interno-, en empresas de limpieza, en la hostelería en tareas de limpieza y como camareras). Solo dos mujeres, y por períodos reducidos, se habían empleado en tareas administrativas.

Por último, las que realizaron la reagrupación familiar de sus hijos tienen grandes dificultades para conciliar la vida laboral y familiar. Al igual que sus

5. El análisis de las condiciones laborales de las trabajadoras domésticas extranjeras merecería un apartado por separado que aquí no podemos desarrollar por cuestiones de espacio. Se trata de un trabajo que, aun regularizado y a pesar de la reciente modificación legal que lo disciplina (RD 1620/2011, de 14 de noviembre), ofrece niveles mínimos de protección. Entendemos que no solo se trata de que estas trabajadoras tengan derechos laborales básicos, sino que también existan medios para que puedan ejercerlos (Anderson, 2004). En el caso de las trabajadoras extranjeras, el acceso a esos derechos está condicionado en buena medida a su residencia legal en el país; pero la perversa vinculación que la Ley de Extranjería establece entre la posibilidad de residir y trabajar legalmente y la presentación de un contrato laboral actúa claramente en contra de este propósito. Difícilmente una empleada del hogar "sin papeles" denunciará condiciones laborales abusivas. Lo mismo podemos decir de las empleadas domésticas regulares, que para renovar sus permisos dependen de la voluntad de sus empleadores de formalizar la relación laboral, lo que pone en evidencia la precariedad y temporalidad de los derechos así adquiridos. No queremos presentar una visión victimizada de las trabajadoras domésticas migrantes, sino resaltar que el solapamiento de la legislación laboral y de extranjería las penaliza doblemente por ser trabajadoras domésticas y extranjeras, ubicándolas en los últimos peldaños de la escala social. 
pares españolas, afrontan "la doble carga de trabajo", pero sin la red de parentela femenina con la que contaban en la sociedad de origen y sin recursos económicos para poder comprar en el mercado los servicios en los que ellas mismas se emplean. A esto se suman las dificultades relacionales con sus hijos, con quienes vuelven a convivir tras muchos años de separación. Problemáticas que, en algunos casos, pueden conllevar el fracaso de la reagrupación y, como consecuencia, el regreso de los hijos - o parte de ellos - al país de origen.

Creemos entonces que precariedad es la palabra que mejor resume la inserción de estas mujeres en nuestra sociedad, a causa fundamentalmente de su triple condición de mujeres, trabajadoras y migrantes (Parella, 2002), y que emerge claramente a partir del análisis de las prácticas que despliegan para afrontar los problemas de salud, cuestión que a continuación pasamos a examinar.

\section{La experiencia de enfermedad: significados, prácticas, recursos e incidencia en el proyecto migratorio}

\subsection{Significados y prácticas}

La metodología cualitativa adoptada en la investigación privilegió el punto de vista de las trabajadoras con la intención de analizar y describir cómo se sitúan y asumen la experiencia de enfermedad durante el proceso migratorio, confiriéndole significados y desarrollando acciones para lidiar con ella.

Con respecto a los significados que adquiere la enfermedad durante la migración, en todos los casos los problemas de salud han aparecido en relación con el sentimiento de miedo o temor o en términos de un problema o preocupación:

Eso es lo que más antes he sentido, es el miedo de enfermarme y de faltar al trabajo, del descuento porque, claro, el dinero cuenta mucho aquí, entonces eso es lo que yo..., pienso eso, ¿no?, de que, de que hay que sacar dinero. $\mathrm{O}$ sea, es como algo, como un robot que tienes que no estropearte porque tienes que hacer esto (Marlene).

Pero ya unos meses, cuando ya iba haciéndome las pruebas [... ], yo ya tenía todo eso, lo tenía en mi cabeza, ¿̇sabes?, preocupación y decir, Dios mío, si me tengo que operar y yo no trabajo todos los días, tengo que pagar el piso, 
el niño, no, no puede ser, ¿¿ios, qué hago?, decía yo, estaba muy preocupada (Roxana).

Frente a la incidencia de los problemas de salud - ya sea por una enfermedad o a causa de un accidente laboral-, la estrategia más habitual que ponen en práctica las mujeres entrevistadas es intentar no dejar de trabajar cueste lo que cueste:

Muchas veces me iba (al trabajo) con fiebre, muchas veces me he ido..., alguna vez me acuerdo que me he ido escondiendo mi catéter, alguna vez me ha caído, me he accidentado así, en el trabajo, me he hecho algo y lo he hecho pasar, ¿no? (Roxana).

Todas las mujeres señalan que han ido y/o van a trabajar estando enfermas, recurriendo en primer lugar a la autoatención por medio de la automedicación. Pero no siempre es posible solucionar el malestar por medio de la automedicación. Cuando el recurso al servicio sanitario resulta impostergable, otras son las estrategias que se despliegan para intentar no dejar de trabajar. Si el médico decreta la baja laboral, una de las prácticas recurrentes es negociarla, generalmente con escasos resultados:

Y de tanto, de mal que me puse que me fui al médico y el médico me dio una incapacidad; entonces luego fui para que me..., pues, como si ya estuviera bien porque yo le dije: 'Yo no me puedo quedar sin trabajo' Me dijo: 'No puedes trabajar así. Si estás..., en esta situación no puedes trabajar.' Todo me dolía a mí, a mí todo me dolía (Mirella).

Y si no se negocia, se intenta evitarla o acortarla ocultando el malestar:

Sí, tuve 15 días [de baja]..., y de ahí yo fui y me dijo: "Mira, ¿ya estás bien?", y yo: "Sí, ya estoy bien", porque yo digo, a ver, lo que tú piensas es que te vas a quedar sin trabajo..., ¿`sabes? Así, entonces te sientes mal... (Carmen).

Como la estrategia de intentar negociar la baja laboral no suele funcionar, algunas de nuestras informantes declararon desconocerla a pesar del esfuerzo físico que supone la actividad laboral que realizan. Este es, por ejemplo, el caso de Rosa, con un profundo corte en la palma de la mano:

Unos dos meses más o menos porque tardó mucho en curar mi mano..., claro, aquí tardó un montón porque no dejé de trabajar [...], curaba por fuera, curaba por fuera, pero por dentro no curaba porque era muy profunda la..., el 
corte, era muy profundo. Pero, bueno, duró dos meses más o menos..., pero, claro, hasta hoy siento un poco de molestia...

Tampoco Susana respetó el período de reposo postoperatorio tras sus dos intervenciones:

La primera fue corta porque fue..., la vesícula tardé un par de semanas en salir a trabajar porque salí a trabajar con faja con la herida puesta [ríe] [...], tenía que hacer un mes o inclusive más porque había tenido una herida bastante profunda en esta zona [estómago], y bueno que..., tenía que estar cuidándome bastante, de no hacer esfuerzo. Al principio iba muy..., muy enfajada para no..., para que no se sienta el esfuerzo en la zona y..., no fue mal, eh [risas] [...]. Y lo del quiste fue..., más o menos era el mismo tiempo de..., de baja, ¿no? [...]. Pero bien que..., lo llevé bien también. Conforme pude me fajé bien y... ide nuevo a trabajar! [risas].

Roxana, en lista de espera para un trasplante de riñón, trabajaba a pesar de la expresa prohibición médica:

Me puse a trabajar [lo dice muy bajo] unas horas de limpieza, es como estoy saliendo [económicamente] [...], en las mañanas voy a limpiar dos horas, tres horas, en una casa, en otra casa, y ahora sí lo tengo más estable, en la tarde pues ya voy a la diálisis [...], ellos [los médicos] no saben que yo estoy trabajando. Así estoy dos horas, una hora, ellos no saben.

Por último, es interesante notar la estrategia que surge del relato de dos mujeres - empleadas en el servicio doméstico por horas - que para hacer frente a los problemas de salud sin dejar de trabajar subcontratan a otra persona para que las ayude a llevar adelante los trabajos más pesados que ellas no pueden realizar. Rosa lo hizo en el caso puntual del accidente en la mano; para Susana, en cambio, es la única manera de poder seguir trabajando en el servicio doméstico visto su actual estado de salud:

[...] porque hay muchas cosas que ya no puedo hacer, ya tiene que hacerlas alguien. Ya llevo alguien para hacerlas por mí. Persianas, cosas así..., no las puedo hacer por el brazo, por la tendinitis [...]; si hago un sobreesfuerzo un día, pues al siguiente no puedo trabajar porque no puedo, no me responde [el brazo]..., me sabe mal..., pero ellas [las ayudantes] también son más jóvenes, más fuertes y no han trabajado tantos años como yo [ríe]. 


\subsection{Recursos para el cuidado de la salud durante la migración}

Al preguntarles quién cuida de ellas cuando enferman, la respuesta, cuando no hay una red familiar en la sociedad de destino, es nadie, que ellas cuidan de sí mismas.

[... ] yo, cuando me pongo malita, yo no tengo quien cuide de mí, no. Si como, bueno, y, si no, también (Mirella).

Yo ya estaba ahí preocupada, estaba asustada porque si voy al hospital, no voy a poder trabajar, no tengo a nadie. ¡Dios mío! ¿Qué va ser de mí! ¿Qué-va-aser-de- mí! (Mónica).

No obstante, creemos que esta respuesta merece ser matizada. El sistema de salud público, las organizaciones del tercer sector y religiosas, el servicio socioasistencial, los empleadores, los amigos y la familia son todos actores que se constituyen como cuidadores, cada uno con sus especificidades y en función de cada caso particular.

En primer lugar, para todas el servicio sanitario público es un recurso fundamental a la hora de atender sus problemas de salud ${ }^{6}$ y coinciden en valorar positivamente las prestaciones sanitarias, la actuación del personal médico y la relación con los profesionales:

Sí, sí, me llevaron y, bueno, a urgencias, me quedé allí, me hicieron las pruebas y me dijeron que la vesícula estaba ya..., ya no servía, había que quitarlo ya. Y sí, muy pronto también, me hicieron todo muy bien (Susana).

Mira, me atendieron como yo nunca imaginaba, magníficamente bien, mira, ahí estaban todos muy pendientes de mirar [... y de verdad no me puedo quejar [...] , de verdad, muy bien, muy bien, muy bien (Rosa).

También muy buena, muy buena, sí, con los médicos yo tengo mucha relación $y$ a veces se involucran a nivel personal en mi vida también porque, claro, saben que yo a mi hijo lo traje muy pequeño. Lo conocieron pequeñito y yo muchas veces he ido a la diálisis y le dejaba a mi hijo afuera en el parque jugando

\footnotetext{
6. La investigación se desarrolló en el marco de una legislación de extranjería que garantizaba el derecho a la asistencia sanitaria en las mismas condiciones que los españoles. Las modificaciones recientes restringieron este derecho a partir del 1 de septiembre de 2012 a los residentes regularmente en el país y a los menores de dieciocho años. Los extranjeros irregulares solo recibirán asistencia sanitaria en caso de emergencia y durante el embarazo, parto y posparto.
} 
o le decía a la enfermera, "vigílalo, que está afuera" y así, sabes. Entonces han ido ellos también un poco conociendo (Roxana).

Solo en un caso, el de Marlene, hemos registrado una apreciación negativa. A su juicio, nunca ha encontrado una respuesta satisfactoria para sobrellevar el estado depresivo y la sensación de estrés que la aquejan, a pesar de que ha acudido al médico por estas cuestiones en diversas ocasiones.

Por otro lado, emerge la importancia que reviste el trabajo en red del servicio sanitario con otras instituciones. Roxana, a partir de su contacto con el servicio sanitario, tuvo acceso a otros servicios para atender problemas no vinculados estrictamente a su salud:

Luego logré hacer los papeles, pues [...] yo ya empecé a enfermar, ya estaba mala, fui al médico, y ellos me dijeron,"Roxana tienes que...", estaba ilegal aún, estaba solamente con..., un..., un visado que ya se me había vencido y todo, entonces, cuando fui al médico me aconsejaron, me dijeron, "mira, tienes que ir a un sitio donde ayudan a hacer los papeles a los inmigrantes para que estés legal, tú estás enferma y necesitarás siempre”. Entonces me fui a unos abogados que había de estos, que ponen, ¿no?, para los inmigrantes...

Y a la inversa, Mirella accedió al servicio sanitario a partir del contacto con otras instituciones:

Me empezaron a dar unas picadas al lado izquierdo [del pecho] y yo fui al médico [... ], había ido al CITE; $;^{7}$ en el CITE me dijeron que fuera al puesto de salud..., donde te ayudan a hacer los papeles y todo..., es una cooperación contigo, te orientan si vas a reagrupar. Sí, en el CITE te orientan, hay Cruz Roja, si no tienes dónde empadronarte te ayudan a empadronarte. $\mathrm{Y}$ yo no estaba empadronada en ninguna parte, pero entonces me dijeron que yo como ser humano tenía derecho a que se me atendiera.

De hecho, para Mirella, que ha padecido múltiples y serios problemas de salud, distintas organizaciones religiosas y del tercer sector han sido su principal punto de apoyo ante la ausencia de una red familiar y social en Cataluña. Los servicios socioasistenciales públicos, en cambio, no aparecen como un recurso siempre disponible:

He recibido más ayuda ahora que estoy empadronada, que tengo documentos y que tal porque si no tienes papeles, nadie te da nada.

7. Centros de información a trabajadores extranjeros (Sindicato Comisiones Obreras). 
De hecho, en las narraciones de las mujeres estos servicios brillan por su ausencia. Solo en el caso de Roxana aparecen como un recurso estable al cual acudir en caso de necesidad:

[...] he tenido a los servicios sociales, "mira, me falta esto"..., alimentos, una semana me daban alimentos, "a mi hijo le falta tal cosa, necesita ir a estudiar tal cosa, hacer un refuerzo". "Venga, vale, vamos a buscar una beca". Y ellas [las trabajadoras sociales] intentan también darme un poco de tranquilidad, sabes, porque saben muy bien mi situación [...].

El empleador, en casos puntuales, también puede ser una fuente de cuidado, proveedor de medios económicos y/o de afecto, pero en el seno de relaciones fuertemente asimétricas que generan gran dependencia e inclusive rayan la explotación:

Porque encontré una vivienda, encontré una persona mayor que me brindó cariño [... ], no me cobraba la vivienda, yo le ayudaba a cambio de comida y dormir [...]. Ella, pobrecita, ya no veía bien [...] que sus platos y sus trastos estaban muy deteriorados y muy sucios, yo se los lavaba, se los mantenía bien, que la mesa del comedor estaba llena de papeles y de basura y había que limpiarlo..., ella no pensaba en esas cosas..., que su baño debía estar higiénico y que tal [...], hasta que yo le dije: "Mire, necesito hacerme los documentos". Una sobrina fue conmigo a distintos sitios y le dijeron que no necesita sino que firmarle una constancia de que ella te trabaja a ti siquiera cuatro horas' [...]. Nunca lo hizo [...] (Mirella).

Susana acudió a uno de sus empleadores cuando tuvo que afrontar momentos de estrechez económica a causa, en parte, de los problemas de salud padecidos. Pero el "compromiso" que dicha ayuda comportó fue un obstáculo, que igualmente logró resolver, a la hora de dejar de trabajar para ese empleador:

[...] la gente con quien trabajo, eh, me costeó, me prestaron, eh. Luego fui, cada semana que yo iba trabajando, pues, te debo 30 euros, te debo 20 euros y así me pasé años pagando [risas] [...], crea mucho compromiso [...]. Es muy pero muy fuerte, eh. Porque sabías que tenías que ir a trabajar, pero en lugar de cobrar 50 euros cobrabas 20 o 30 [...], yo le debía dinero y, uf, ya no podía, ya no soportaba ir. Sí, estaba muy, muy..., entonces empecé a intentar arreglar un poquito cómo dejarla porque son las personas que me hicieron los papeles, ¿̇no? Eso fue una familia. Pues yo trabajo con la familia, con la 
madre y con los cuatro hijos. ¿Cómo dejas la madre y a los hijos no? Entonces, pues, empecé a quejarme mucho del brazo [...] ya no podía más porque ahí se exigía demasiado, ella no quería que la dejara, pues entonces le dije: "Mira, yo no puedo sola ya. ¿Por qué no contratamos, no buscamos otra chica?". Se lo dije a su marido, "buscamos a otra chica que me ayude, yo sola no puedo ya". Pues buscamos a otra chica. Esperé un tiempo prudencial hasta que la chica se adaptó a la casa y entonces fue cuando pegué el cambiazo [risas].

También, para algunas, los amigos son una fuente de cuidado, aunque a menudo estos son también migrantes y, por ello, son escasos los recursos que pueden proporcionar:

Ahora ya es mi prioridad comer bien, estar bien porque es que no tengo a nadie, como no tengo a nadie, ¿quién va a velar por mí? Yo sé que tengo amigos que me quieren, pero no es igual, no es igual. No puede ser igual porque ellos tienen su vida. Si estuviera mi hermana, sí, si estuviera mi papá, sí [...], pero una amiga, igualmente están mis amigas en la misma situación que yo, ¿qué pueden hacer por mí? (Mónica).

Por último, aquellas que cuentan aquí con una red familiar tienen su apoyo, sobre todo por parte de las mujeres de la familia, lo que confirma el carácter femenino de las tareas de cuidado:

[...] estamos muy unidos nosotros, los diez hermanos, siempre nos juntamos cada fin de semana en la casa de mi madre [.... . O ellos vienen a verme [...]. Yo si estoy ingresada y eso, ellos se dedican a mi hijo, mi hermana, mi madre, le dejan la comida, le ayudan un poco y esto..., es una tranquilidad [...], yo siempre estoy apoyada por ellos [...], mi hermana la pequeña, la que vive con mi madre, es la que me iba a donar el riñón y no ha salido bien. Pero siempre están pendientes de todo (Roxana).

Pero tal como sucede con los amigos, a menudo son escasos los recursos que pueden brindarles, especialmente los de tipo económico. Por otro lado, es interesante notar que, aunque la familia se encuentre en la sociedad de origen, igualmente puede ser una fuente de cuidado a distancia. Este es el caso de Marlene, que comparte experiencias y pide consejos a su madre en Ecuador:

Y así he ido, un poco con dolores de cabeza, dolores de cabeza y el médico: "No, que eso es normal". Y no me recetaban jamás nada, y yo, bueno. Y claro, 
yo llamaba a mi madre, que también ella tiene su edad, y mi madre me decía: "No, eso no es así", dice: [ [...] tú has de estar, es que... los nervios y así...

\subsection{Incidencia en el proyecto migratorio}

Algunas investigaciones han mostrado que los inmigrantes priorizan la obtención de dinero por encima de cualquier consideración de su propia salud (Bermúdez, 2004; García et alii, 2009). La puesta en marcha de las estrategias examinadas al inicio de este apartado pareciera a primera vista confirmar esta afirmación. Sin embargo, creemos que la interpretación de estas no puede separarse de la triple condición de mujeres, trabajadoras y migrantes, que actúa de manera entrelazada en su vida cotidiana y que determina su precaria inserción en nuestra sociedad.

Faltar al trabajo significa perder la ganancia de los días no trabajados e inclusive puede llegar a significar la pérdida del empleo, lo cual hace peligrar la propia manutención y la de la unidad doméstica, ya se encuentre en la sociedad de destino o en la de origen:

Mira, que podría irme corriendo al médico diciendo: "Mira, oye, que estoy con..., me está bajando mucho esto [pérdidas de sangre] y estoy así". Pero no, sigo mi trabajo y estoy ya mis horas [...], el que tiene hijo sabe lo que cuesta un hijo. Mis hijos, claro, usted ni nadie tiene culpa de mis errores míos porque son mis hijos, ¿no?, claro, porque nadie me ha dicho vete a país ajeno, ¿no? (Carmen).

[...] hay que tener en cuenta que para mí siempre lo primero es mi hija [...], y si yo tengo que atenderme a mí también, todo ese tiempo que yo no estoy trabajando es el tiempo que yo no estoy ganando y estoy perdiendo porque entre que no trabajo, no gano, y entre que gasto, entonces al final... (Susana).

Además, si los problemas de salud han sido graves y prolongados como en el caso de Roxana y Mirella, sus trayectorias laborales aparecen extremadamente discontinuas, lo que determina una gran inestabilidad económica que repercute negativamente en las condiciones habitacionales:

Yo ahora pago mi habitación y no consiento que nadie se me pase a la habitación..., y a cada uno, a su sitio. Entonces, ahí, ahí, no dos, hay tres hombres ahí, a veces hay cuatro o cinco y yo a cada uno a su lugar, a su lugar, a su lugar 
[...], hacía muchos años que no me sentía bien. Siempre..., no he durado ni 15 días en las casas y andaba con todo en un trastero, pagaba 80 euros de trastero para yo poder sobrevivir en los sitios donde iba. Tenía que ir huyendo de todos los sitios porque yo quería una vivienda, yo no podía vivir, entonces..., en cambio, allí no, allí [...] nadie me molesta, hasta aquí, ya llevo 4 meses y no me molesta nadie. Que lucho por conseguir esos 250 mensuales pero..., estoy bien (Mirella).

Ninguna era propietaria de su vivienda en Cataluña (dos lo eran en la sociedad de origen). No creemos que sea correcto relacionar el régimen de tenencia de la propiedad con su situación de salud, pero seguramente este factor puede actuar en contra. De hecho, el pago del alquiler es una de las mayores preocupaciones ante la incidencia de los problemas de salud:

Siempre he tenido preparado el alquiler, que es lo más importante y..., y $\mathrm{pa}^{\prime}$ la comida, que son las dos cosas, digamos, esenciales $y_{\ldots} . .$, bueno [...], lo del alquiler $y$ todo cuando he tenido que hacer estas cosas [intervenciones quirúrgicas], lo primero es pensar cómo vas a pagar el alquiler, eh, porque el alquiler llega y hay que pagar (Susana).

Solo dos mujeres vivían en pareja, Carmen y Rosa, pero únicamente el compañero de Rosa contribuía económicamente. El de Carmen se encontraba desocupado sin prestación de desempleo. La familia sufragaba los gastos de manutención del hogar juntando el salario de Carmen y el de su hija mayor. En los otros casos, ellas eran las únicas proveedoras de su manutención y, según los casos, también de su familia en la sociedad de origen y/o destino. Solamente una de ellas tuvo acceso a una ayuda pública para resolver el alquiler de la vivienda.

El trabajo, además, siempre que se realice en condiciones regulares, es la condición sine qua non para que ellas y sus familias residan legalmente en España. Por eso, en el contexto de una legislación de extranjería de carácter marcadamente laboral, la enfermedad incide negativamente en su ya precaria situación jurídico-administrativa. Aunque en ninguno de los casos se ha verificado la caída en la irregularidad como consecuencia de los problemas de salud, algunas mujeres han tenido problemas para renovar las tarjetas de residencia y trabajo, realizar la reagrupación familiar y/o nacionalizarse españolas. 
Roxana, en sus primeros años de estadía, regularizó su residencia a causa de su problema de salud, pero, paradójicamente, este mismo motivo actuó en contra cuando renovó su autorización de trabajo (obtenida en un segundo momento), empujándola a emplearse aun cuando su estado de salud no lo permitía:

[... ] yo de cara cuando sabía que tengo que renovar y eso yo me espabilaba en buscarme un trabajo, sabes, en donde me hagan contrato y me sirva para ir renovando. Eso sí, nunca me he descuidado. Yo ya me lo iba montando todo porque yo sabía que era un requisito, que era importante eso, estar trabajando y tener un contrato, entonces yo intentaba por todos los medios, aunque esté enferma, aunque esté como sea, de ponerme a trabajar y tener un contrato para presentar.

Gracias a esta estrategia, Roxana ha renovado siempre su documentación. ${ }^{8}$ Pero le denegaron la reagrupación del hijo, quien finalmente ingresó en España con un visado de turismo:

Me denegaron [la reagrupación familiar], me denegaron, siempre, sí [...], porque era, claro, yo al estar enferma no tenía un trabajo muy, sabes, seguido y eso, todo eso influía mucho y te piden todos los requisitos y que tal, no se qué, un contrato, tanto..., y yo no llegaba..., no reunía los requisitos.

Mirella también tuvo problemas para renovar sus "papeles":

Me estuve a punto de perder los papeles, pero como he estado en lo del itinerario de búsqueda de empleo, esa justificación me ha servido y el asistir a talleres, que he asistido a talleres y los trabajos [...], estuve haciendo acogidas, estuve yo también en otros sitios recibiendo acogidas. Y entonces me han dado un certificado como que yo estaba llevando un itinerario de búsqueda de empleo y por favor que..., que yo era una persona que tenía integración con la sociedad y todo eso, me han dado un dossier para que lo presentara en el Gobierno Civil. Se exigía al Gobierno que me aceptara y con eso se me renovaron los papeles. ¡Gracias a Dios!

Pero su solicitud de nacionalización fue denegada por no poder demostrar poseer medios de vida suficientes, una consecuencia de su precariedad laboral fruto de su frágil condición de salud.

8. Ha obtenido inclusive la nacionalidad española, lo que sin dudas le proporciona una mayor estabilidad y, con ello, un problema menos del que ocuparse cuando su estado de salud le imposibilita trabajar. 
El caso de Susana es emblemático en relación con las dificultades jurídicoadministrativas que produce la enfermedad. La primera operación a la que se sometió coincidió con el período de solicitud de reagrupación de sus hijos. No respetó el reposo postoperatorio porque:

[... ] no podía no cobrar y yo necesitaba trabajo, necesitaba el dinero [...], tenía el piso alquilado yo. Estaba en el período..., de solicitud de reagrupación, estaba en ese período, todo, y eso me vino así una cosa muy repentina, así que fue..., fue todo en ese lapso de..., de la solicitud de papeles de mis hijos, y todo eso.

Además, para poder afrontar el gasto de la reagrupación familiar — alquiler del piso, billetes de avión, trámites administrativos-, dejó de pagar la cotización a la Seguridad Social, lo que a su vez le ocasionó problemas para renovar su tarjeta de residencia y la de sus hijos ya reagrupados. ${ }^{9}$ La deuda con la Seguridad Social (1.600 euros) la saldó pidiendo un préstamo a uno de sus empleadores y así pudo renovar los permisos.

Queda claro que el trabajo constituye el eje vertebrador de la experiencia migratoria de estas mujeres. Good señala, para el caso de las personas afectadas de enfermedad crónica, que el intento de llevar una vida profesional a pesar de la enfermedad puede ser entendido "como un esfuerzo para contrarrestar la destrucción del mundo vital" (2003: 236). Los testimonios revisados nos inducen a pensar que algo similar sucede cuando la enfermedad irrumpe durante la migración.

En los discursos de las mujeres emerge con fuerza su identidad de trabajadoras:

Pero que lo mío ha sido positivo. Yo salgo acá a la calle, a mí la gente me conoce como a una trabajadora (Susana).

Y no son simplemente trabajadoras, son además "responsables" y "cumplidoras":

[... ] a mí no me gusta dejar mi trabajo. Mira, si tengo que limpiar una casa hoy (y no puedo ir), me sabe malísimo porque no me gusta quedar mal con la gente [...], a mí me gusta cumplir (Rosa).

9. Estaba afiliada al hoy desaparecido régimen discontinuo de trabajadoras domésticas. Luego de este incidente supo que se podía dar de alta y de baja a conveniencia. Durante los siguientes años empleó esta estrategia para maximizar sus ingresos, siempre asegurándose de cotizar el período suficiente para poder renovar su permiso de residencia y trabajo. 
Y yo pienso que la responsabilidad hay que tenerla siempre, si eres responsable de un trabajo no puedes decir "oye, mañana no voy" [...], tiene que ser porque no has podido en realidad, entonces yo digo "pues no puedo". Pero que yo me pueda levantar de la cama, ¡olvídese! Que yo..., que yo cojo el camino... (Carmen).

El vacío que provoca la enfermedad cuando impide trabajar es vivida como la negación de la condición de inmigrante (Sayad, 2002). Inclusive puede determinar el fin de la experiencia migratoria. El retorno, muy presente al inicio de la trayectoria migratoria, pierde vigor con el paso de los años para reaparecer con los problemas de salud. Los que tiene Susana, aunque no la inhabilitan para seguir trabajando, le impiden cumplir largas jornadas laborales en el servicio doméstico y mantener el mismo nivel de ingresos. La escasa movilidad laboral de esta actividad le dificulta encontrar otra ocupación menos demandante físicamente. El retorno, entonces, emerge como una posible solución:

[...] porque he sido muy bruta. He sido..., yo nunca me he mirado en ese aspecto, yo siempre he mirado en cuanto al trabajo y no me he mirado mucho. $\mathrm{Si}$ hay que hacer se hace, si hay que esforzarse se esfuerza. Si hay que romperse, uno se rompe. Pero que no me he estado mirando yo por mí, entonces claro, estoy ya $[\ldots]$, ahora ya no hago tantas horas como antes, ya no puedo [...], voy [a trabajar] con faja, voy medicada ya y todo eso, entonces ya no puedo trabajar tanto como antes [...] , si yo no puedo ganar lo que ganaba antes, tampoco voy a llevar la calidad de vida que llevaba ni tampoco voy a poder darle calidad de vida a mi hija. O sea que, entonces no es..., porque claro, aquí siempre voy a vivir de alquiler. No es una hipoteca, pero es un alquiler que siempre hay que pagar..., yo no voy a tener a mi hija mal. Para tenerla mal, nos vamos [a Paraguay], que ahí tenemos una casa.

En su relato, junto al trabajo, las motivaciones familiares - sobre todo el fracaso de la reagrupación de su hijo mayor- son relevantes para justificar la vuelta:

Yo al final, en cuanto pueda, yo me regreso a mi país con mi hija porque al irse mi hijo es también como un desprendimiento..., porque la idea es que estuviesen los dos juntos [...], mi idea nunca fue realmente volver a Paraguay porque por eso yo he hecho las documentaciones legales para traer a mis hijos. ¡Me esperé cinco años para traerlos! Y... ¡Me costó mucho traerlos! Pero al 
irse mi hijo también fue un, como te expliqué antes, un desprendimiento muy grande para mí, porque yo los quería a los dos juntos y no puede ser, o sea, que no podemos estar uno en una punta y otro en el otro.

Mirella también fantasea con el retorno. Su estado de salud le ha impedido estabilizarse económicamente, y ahora su edad limita su posibilidad de emplearse en el servicio doméstico, sin otras alternativas de trabajo formal a la vista; pero no logra ver con claridad su futuro, ni en España ni en Colombia, porque no cuenta con una red familiar en ninguna de las dos sociedades. Roxana, en cambio, confirma la importancia que reviste la familia en la trayectoria migratoria. Su delicado estado de salud la aleja de la idea del retorno justamente porque en la sociedad de destino cuenta con una extensa red familiar.

[...] ahora con la crisis hay mucha gente, familiares que tengo yo, de muchos años que se están volviendo a Perú, pero eso a mí no se me cruza por la cabeza por mi enfermedad. Igual, si yo estaría sana, igual sí, podría pensármelo un poco, oye, mira, yo creo que allí, no sé, me compraría mi casa, me iría mejor allí y ya, mira, también me iría un tiempo porque yo tengo la nacionalidad y si no me va bien, pues vuelvo, no sé qué, pero no, no se me cruza eso. ¿Por qué? Porque ya mi hijo también ya, un chaval que ya se ha criado aquí, estudia aquí, ya tiene..., y también mi familia está haciendo la vida aquí.

En síntesis, vemos que la enfermedad irrumpe en un contexto de fuerte exclusión social, muchas veces acompañada de la falta de vínculos familiares y sociales fuertes en la sociedad de destino. Por ello, si el estado de salud impide seguir trabajando, el retorno se dibuja como una de las posibles soluciones. Pero esta decisión aparece íntimamente relacionada con motivaciones familiares, las cuales también son centrales a la hora de emprender la empresa migratoria.

\section{Conclusiones}

Entendemos que las prácticas que las mujeres despliegan frente a la incidencia de los problemas de salud aparecen, más que como una solución, como una expresión de la criticidad de sus condiciones de vida y trabajo. La automedicación, negociación y/o desconocimiento de la baja laboral o la subcontratación de otra trabajadora son todas estrategias dirigidas a contener el efecto desestabilizador que la enfermedad provoca en el frágil equilibrio con- 
struido en esta sociedad en torno a un trabajo que ofrece niveles mínimos de protección, pero que constituye el eje vertebrador de su experiencia migratoria.

A esto se suma que la atención de sus padecimientos se desarrolla en un contexto en el que las redes familiares y sociales pueden ser muy débiles y en el que las respuestas desde las instituciones públicas para contener la altísima vulnerabilidad a la que están expuestas resultan claramente insuficientes.

Lo anterior nos lleva a pensar que el análisis de la experiencia de enfermedad resulta de gran utilidad para estudiar las condiciones de inserción/exclusión de los migrantes en la sociedad de destino. Aquí hemos centrado nuestra atención en el caso particular de las trabajadoras domésticas de origen latinoamericano. Indudablemente, su migración comporta especificidades relacionadas con su triple condición de mujeres, trabajadoras y migrantes (Parella, 2002) y su inserción en el proceso actual de mercantilización e internacionalización del trabajo reproductivo. Una mirada atenta a las relaciones sociales en las que se sustenta dicho proceso permite entrever que las desigualdades existentes en la sociedad global no solo son de clase, sino también de género y etnia, y, además, que no solo se estructuran entre el centro rico y la periferia pobre del mundo, sino también en el seno de los Estados centrales.

Así pues, creemos que profundizar en el conocimiento en este ámbito puede contribuir a ampliar nuestra mirada sobre los actuales flujos migratorios internacionales femeninos, ponderando el proceso de empoderamiento de las trabajadoras migrantes referido en la bibliografía especializada en el marco de las condiciones estructurales en las que se desarrolla su proyecto migratorio. Este es un tema que esperamos poder desarrollar en futuras investigaciones.

\section{Bibliografía}

Anderson, B. (2004): "Just another job? The commodification of domestic labour". En B. Ehrenreich y A. Hochschild (eds.): Global woman. Nannies, maids, and sex workers in the new economy. Nueva York: First Holt Paperbacks Editions, pp. 104-114.

Bardají, F. (2006): Literatura sobre inmigrantes en España. Documentos del Observatorio Permanente de la Inmigración, núm. 13. Madrid: Ministerio de Trabajo y Asuntos Sociales. 
Bermúdez, E. M. (2004): "Imágenes de la salud y la enfermedad de las mujeres colombianas inmigrantes en España”. Gerencia y Políticas de Salud, vol. 3, núm. 7, pp. 78-100. Pontificia Universidad Javeriana.

Bodoque, Y. y Soronellas, M. (2010): "Parejas en el espacio transnacional. Los proyectos de mujeres que emigran por motivos conyugales". Migraciones Internacionales, vol. 5, núm. 3, enero-junio, pp. 143-174.

Bover, A. (2006): "Trabajadoras latinoamericanas inmigrantes como cuidadoras: globalización, promoción y acceso a la salud". Nure Investigaciones, núm. 21, marzo-abril.

Burillo-Putze, G. y Balanzó, X. (2010): “Desmontando tópicos sobre migración y salud”. Anales del Sistema Sanitario de Navarra, vol. 33, núm. 2, mayo-agosto, pp. 127-131.

Ehrenreich, B. y Hochschild, A. (eds.) (2004): Global woman. Nannies, maids, and sex workers in the new economy. Nueva York: First Holt Paperbacks Editions.

García, A. M. et alii (2009): "Condiciones de trabajo y salud en inmigrantes (Proyecto ITSAL): entrevistas a informantes clave”. Gaceta Sanitaria, núm. 23, vol. 2, pp. 91-99.

Gentil, I. (2009): "Salud y mujeres inmigrantes latinoamericanas. Autoestima y resiliencia". Index de enfermería, vol. 18, núm. 4, octubre-diciembre.

Goldberg, A. (2003): Ser inmigrante no es una enfermedad: inmigración, condiciones de vida y de trabajo. El proceso de salud/enfermedad/atención de los migrantes senegaleses en Barcelona [en línea]. Tarragona: Universitat Rovira i Virgili, Departamento de Antropología, Filosofía y Tabajo Social, <http:// www.tdx.cat/TDX-0704107-141859> [Consulta: 28/12/2011].

Good, B. J. (2003): Medicina, racionalidad y experiencia. Una perspectiva antropológica. Barcelona: Edicions Bellaterra, Serie General Universitaria, 25. Gregorio, C. (2010): “Debates feministas en el análisis de la inmigración no comunitaria en el Estado español. Reflexiones desde la etnografía y la antropología social”. Relaciones Internacionales, núm. 14, junio 2010, pp. 93 115. Grupo de Estudio de Relaciones Internacionales, Facultad de Derecho, Universidad Autónoma de Madrid.

Guarnizo, L. E. y Sørensen, N. N. (2007): "La vida de la familia transnacional a través del Atlántico. La experiencia de la población colombiana y dominicana migrante en Europa”. Puntos de Vista, núm. 9, año III, pp. 7-28. 
Cuadernos del Observatorio de las Migraciones y de la Convivencia Intercultural de la Ciudad de Madrid.

Hochschild, A (2001): "Las cadenas mundiales de afecto y asistencia y la plusvalía emocional”. En A. Giddens y W. Hutton (eds.): La vida en el capitalismo global. Barcelona: Tusquets Editores.

Hondagneu-Sotelo, P. y Ozyegin, G. (2008): "Conclusion: Domestic work, migration and gender order in contemporary Europe". En H. Lutz (ed.): Migration and domestic work. A European perspective on a global theme. Surrey: Ashgate Publishing Limited, pp. 195-208.

Jiménez, B. C. y Redondo, A. (2007): “Mujeres inmigrantes en la ciudad de Madrid: algunos aspectos sobre su inserción laboral, conciliación familiar y salud”. Anales de geografía, vol. 27, núm. 2, pp. 59-76.

Morokvasic, M. (2007): "Migración, género y empoderamiento". Puntos de Vista, núm. 9, año III, pp. 33-51. Cuadernos del Observatorio de las Migraciones y de la Convivencia Intercultural de la Ciudad de Madrid.

Parella, S. (2002): La internalización de la reproducción. La inserción laboral de la mujer inmigrante en los servicios de proximidad. Tesis doctoral Universidad Autónoma de Barcelona, Departamento de Sociología.

Parreñas, R. (2001): Servants of globalization. California: Stanford University Press.

Pedone, C. (2006): "Los cambios familiares y educativos en los actuales contextos migratorios ecuatorianos: una perspectiva transatlántica”. Athenea Digital, núm. 10, pp. 154-171.

Río, M. J. et alii (2003): "Las mujeres inmigrantes en Sevilla: salud y condiciones de trabajo. Una revisión desde la medicina social”. REIS, vol. 104, pp. 123-144.

SAnz, J. (2007): "Entre "cumplir" y "hacer cosas": significados sociales y culturales en torno al envío de remesas en la inmigración ecuatoriana en España". Actas del 5. Congreso sobre la Inmigración en España. Migraciones $y$ desarrollo bumano. Valencia: DEIM y Universidad de Valencia.

SAyad, A. (2002): La doppia assenza. Dalle illusioni dell'emigrato alle sofferenze dell'immigrato. Milán: Raffaello Cortina Editore. 